\title{
Barthes, leitor de Malraux: uma ocultação terrorista
}

Julien Dieudonné

A recente biografia que Olivier Todd* dedicou a Malraux encontrou tanto na França quanto nos países francófonos uma

(Todd, Olivier. André Malraux, une vie. Paris: Gallimard, 2001) acolhida crítica, mais exatamente mediática (tão curto era precisamente o recuo crítico), fora do comum. Na França, a maioria dos suplementos literários dos grandes jornais (Libération, Le Figaro, Le Monde), os semanários de informação (Le Nouvel Observateur, L'Express, Le Point, Marianne) e até mesmo o sacrossanto e doravante falecido programa de televisão "Bouillon de culture", de Bernard Pivot, deram-lhe cobertura, publicaram artigos de primeira página, dossiês ou apresentação especial.

Foi, em geral, para comemorar uma operação de desmistificação bem sucedida e saudar as revelações (parcas, no entanto) sobre mentiras, invenções e delírios mitômanos do escritor elevado à glória do Panteão em 1996 - sem que se dessem ao trabalho nem de medir o real aporte da pesquisa do biógrafo depois dos livros de Robert Payne, Jean Lacouture ou Curtis Cate*, nem de levantar os inúmeros erros, insinuações ou manipulações que enfeitam o livro. Em poucas palavras, tudo aconteceu como se a obra de Todd levantasse um tabu e permitisse que, enfim, a impostura viesse a público: a impostura de um falso grande homem cujos encontros regulares com a História tivessem sido fiascos, e, sobretudo, de um grande falso escritor cuja criação tivesse sido superestimada. Pois as censuras de Todd em relação a Malraux não se limitam nem ao homem, nem mesmo ao homem político: atingem a própria obra, da qual só subsistem, ao fim e ao cabo, obras de adolescência sem importância, romances, quando muito, de sucesso relativo, escritos sobre arte excessivamente complicados e memórias, mesmo tratando-se de Antimemórias, falseadas.

Diante dessa obstinada desmontagem, poucas vozes se levantaram fora do estreito círculo dos especialistas, evidentemente suspeitos de parcialidade. É que a operação encontrou no meio intelectual e universitário um campo favorável: a figura 
'(Barthes, Roland. CEuvres complètes. Paris: Seuil, t. 1: 1993, t. 2: 1994, t. 3: 1995 Todas as citações desta edicão serão referidas aos três tomos dessa edição, respec tivamente abreviadas em I, II e III)

' “A ce moment-là (vers 1936), je n'avais pas d'approche véritable vers la littérature. Les écrivains contemporains que je connaissais, c'étaient les grands noms: Gide, Valéry; ou alors ceux qui arrivaient dans une sorte d'atmosphère d'avant. garde: Malraux ou Céline, par exemple" (II: 988)

- "Adolescent, j'ai été un très grand lecteur, sinon un très bon lecteur; après, j'ai moins lu" (II: 988)

• "Ce qui me dépaysait en lui, c'est que j'avais l'impression qu'il était intelligent par hasard" (III: 453) de Malraux, tanto a do escritor quanto a do homem, goza aí, pelo menos desde sua morte em 1976, de um singular desafeto.

A quem quisesse compreender as razões de uma repulsa tão constante, parece que as poucas alusões que Barthes dedica a Malraux poderiam, apesar de sua exigüidade, oferecer uma densidade instrutiva. Quando Barthes lê Malraux, encontramos com efeito interligados dois problemas, um político e outro retórico, que não desconhecem nem o desafeto contemporâneo nem os anátemas do último biógrafo em data.

A primeira constatação já é muito reveladora: a escassa presença, ou melhor, a quase ausência de Malraux nos textos de Barthes. Nas 3.700 páginas das Obras completas ${ }^{*}$, só encontramos um único texto realmente dedicado a Malraux e somente doze menções a seu nome, a maioria no âmbito de conversas ou debates. Quando incluída em um livro ou em um artigo, a menção só aparece em nota. Presença literalmente marginal: visivelmente, para Barthes, a obra de Malraux não conta - ou mais exatamente: não conta mais. Pois essa ocultação esconde uma rejeição. É que Barthes não foi sempre, se pudéssemos ousar assim dizer, dominado por essa "fobia malruciana". Em uma conversa, "Crítica e autocrítica”, publicada em Les nouvelles littéraires em 5 de março de 1970, evoca suas leituras de juventude: “Àquela altura [por volta de 1936], eu não tinha um verdadeiro interesse pela literatura. Os escritores contemporâneos que conhecia eram os grandes nomes: Gide, Valéry; ou então os que surgiam em uma certa atmosfera de vanguarda: Malraux ou Céline, por exemplo"**.

Há de se notar que a confissão não se faz sem reserva. Essa “certa atmosfera de vanguarda” deixa supor um certo ar de trapaça. Aliás, Barthes tem o cuidado de acrescentar: "Adolescente, fui um grande leitor, quando não um muito bom leitor; depois, li menos"*. Mau leitor: outra forma de dizer leitor de literatura ruim?

Mas estávamos falando de um texto, um único, dedicado a Malraux. Intitula-se “Opinião sobre André Malraux". Foi escrito por ocasião de sua morte e publicado em Le Nouvel Observateur, a 23 de novembro de 1976. Tem uma linha e meia. Espero que me perdoem por citá-lo na íntegra: "O que me desconcertava nele é que me parecia que era inteligente por acaso". "Lacônico. Poder-se-ia até mesmo dizer que parece polido. É uma forma como qualquer outra de sequer falar dos livros. 
Mas este é o Barthes crítico. Não em qualquer lugar: em Lettres Nouvelles, templo da nova crítica. No número 8, a 22 de abril de 1959, Barthes afronta o Ministro da Cultura. Malraux acaba de lançar seu projeto de reforma dos teatros nacionais. O projeto é ambicioso. Nem tanto. Com o título "Tragédia e grandeza", eis o que escreve Roland Barthes: "Diante da distância entre pretensão e decisão, a última reforma dos teatros nacionais tem algo de ainda mais bufão do que as outras"*. O tom é polêmico. Malraux, escreve Barthes, "fala a língua da revolução total, tudo isso para fazer representar um pouco mais Racine e Claudel, um grande escritor católico e nosso clássico mais querido"*. E, continua ele, para colocar à frente dos teatros nacionais administradores e artistas formados, promovidos nesse mesmo regime e nessa mesma estética que pretendem liquidar em nome de uma nova idéia de cultura*. Barthes conclui sua diatribe: "Não se pode contentar o Sr. Kemp1 e a revolução: é preciso escolher. Malraux escolheu o Sr. Kemp"**.

Estamos no centro de um problema de geração, ao mesmo tempo político, colocado por Malraux no pós-Guerra. Tratase do "gaullismo" em uma França em que os intelectuais e a nova crítica se gabam de marxismo, onde a Universidade prepara o movimento de maio de 1968. Um "gaullismo" tanto mais escandaloso pelo fato de ser o do ex-campeão da literatura engajada antes do tempo, o do opositor do colonialismo da Indochina, do militante antifascista, do romancista do Tempo do desprezo e do fundador da Esquadrilha Espanha. Em suma, o problema de Malraux é ainda mais sua mudança de posição do que seu "gaullismo": sua traição. Portanto é violentamente rejeitado pelos reacionários. Encontramos hoje esse problema político, porém ao inverso. Desde então, é menos o "gaullismo" de Malraux que levanta suspeita e condenação do que a camaradagem comunista dos anos 1930 ou sua entrada, julgada tardia, na Resistência. Olivier Todd, em um capítulo intitulado "Os camaradas soviéticos”, consegue (graças a uma manipulação das datas das intervenções do escritor e de uma reconstituição duvidosa dos acontecimentos ${ }^{2}$ ) fazer daquele que, no primeiro

${ }^{1}$ Crítico literário e crítico de arte, membro da Academia Francesa, é, para Barthes, o modelo do crítico acadêmico e conservador.

${ }^{2}$ Ver Jean-Pierre Morel, "L'Hôte non invité? Malraux à Moscou (août 1934)". Em: Malraux, d'un siècle l'autre, Actes du colloque de Cerisy-la-Salle. Paris:
* "Par l'écart des préten. tions et des décisions, la dernière réforme des Théâtres nationaux a quelque chose d'encore plus bouffon que les autres" (I: 814)

"parle le langage de la révolution totale, tout cela pour faire jouer un peu plus Racine et Claudel, un grand écrivain catholique et notre classique le plus choyé" (I: 814)

" "formés, promus dans ce même régime et cette même esthétique qu'ils ont charge de liquider au nom d'une nouvelle idée de la culture" (I: 814)

" "On ne peut pas contenter M. Kemp et la révolution: il faut choisir. Malraux a choisi M. Kemp" (I: 814) 
- "les véritables sujets de la création culturelle sont les groupes sociaux et non pas les individus isolés".

'(Em: France Observateur, 5 de dezembro de 1963)

Congresso dos escritores soviéticos de Moscou, em agosto de 1934, ousou denunciar o dogma do realismo socialista e afirmar o direito imprescritível do artista de criar, fora de toda doutrina ideológica, um defensor de Stálin. Embora tendo mudado de figura ou de cor, o problema permanece o mesmo: trata-se sempre de mascarar uma obra por detrás de um personagem público e de condenar unanimemente a obra e a pessoa, em nome de uma axiologia de suas tomadas de posição públicas que flutua ao gosto da época.

É claro que essa rejeição quando feita, como em Barthes, em nome do marxismo, nem sempre é simples. Pois Malraux é, apesar disso, o autor de A esperança. Lucien Goldmann não se engana quando, em sua obra Por uma sociologia do romance, publicada em livro em 1964, escolhe $A$ esperança para ilustrar a sua tese de obediência marxista. Faz desse romance até mesmo um exemplo dos romances de herói problemático cujos valores qualitativos se confrontam com "uma sociedade produtiva para o mercado", em que os valores de uso desaparecem em proveito dos valores de troca. A esperança é também o modelo de um romance cujos "verdadeiros agentes da criação cultural são os grupos sociais e não os indivíduos isolados"*. Em suma, para Goldmann, Malraux é o autor de um grande romance marxista, embora sem essa intenção.

Quando Barthes resume o livro de Goldmann, em "Les deux sociologies"*, é em tom de elogios que o faz. Mas como conciliar esses elogios com a promoção ao nível de modelo dos romances de Malraux? Barthes resolve o impasse com um adjetivo.

Nos romances de herói problemático [...], há coincidência direta, imediata, entre a estrutura econômica e a estrutura romanesca, entre a inautenticidade do mundo em que vive o herói e o reino todo-poderoso de uma economia cujos valores de troca ("reificantes") suplantaram os valores de uso, aos quais o criador
Dans les romans à héros problématique [...], il y a coïncidence directe, immédiate, entre la structure économique et la structure romanesque, entre l'inauthenticité du monde où vit le héros et le règne tout-puissant d'une économie où les valeurs d'échanges ("réifiantes") ont supplanté les valeurs d'usage, auxquelles le

Gallimard, 2002: 277-289; e Julien Dieudonné, "Pensée sur l'art et l'engagement politique chez André Malraux: les discours des années 30 et le réalisme socialiste”. Em: L'Ecole des Lettres, número especial, novembro de 2001: 99-114. 
e seu herói se acham no entanto ligados; de Stendhal ao primeiro Malraux, esse tipo de romance corresponde bem ao desenvolvimento da burguesia, mas não é de forma alguma a expressão da consciência coletiva burguesa. créateur et son héros restent pourtant attachés; de Stendhal au premier Malraux, ce type de romans correspond bien au développement de la bourgeoisie, mais n'est nullement l'expression de la conscience collective bourgeoise*.

Haveria assim um primeiro Malraux, felizmente revolucionário; porém um segundo vergonhosamente reacionário. E ainda mais: a existência embaraçosa do segundo justifica retrospectivamente que se veja com desconfiança a sinceridade ou a confiabilidade do primeiro. Voltemos a "Tragédia e nobreza", o texto que Barthes dedica à reforma dos teatros nacionais. Vê-se aí, com efeito, como Barthes desliza de um ponto de vista político para um ponto de vista retórico, e como a desqualificação da figura do escritor pode atingir até o primeiro Malraux, ao utilizar a máscara de um argumento retórico. Pois, uma vez colocada em questão a sinceridade das veleidades revolucionárias do ministro, todas as demonstrações de ambição revolucionária, por mais fortes e resistentes que sejam, são lidas como signos de um verbalismo que busca dissimular, sob uma retórica progressista, ambições de poder e intenções de reacionário. $\mathrm{O}$ texto de Barthes não cessa de denunciar no discurso do ministro um álibi, de fustigar uma "economia astuciosa"* Malraux, explica Barthes, contenta-se em "tomar um tom épico e sublime, coisa em que é imbatível”". O ponto de vista de Barthes sobre a retórica de Malraux é, pois, o de um terrorista, no sentido que Paulhan deu a esse termo em suas Fleurs des tarbes, sempre pronto e disposto a ver nas palavras do outro as marcas de um verbalismo. É preciso tomar grandes medidas, proclama Malraux. Delito de formalismo, retorque Barthes: "A nobreza é uma virtude da escritura, uma vestimenta da alma, aqui, o alexandrino, lá o castelhanismo das paixões. [...] Define-se (a Tragédia) unicamente como um tom, uma maneira decorativa de articular os sentimentos*.

Desde então, sempre que Barthes aborda (raramente) o escritor Malraux, é para relegá-lo do mesmo modo ao campo do conservadorismo, dos dinossauros de uma literatura ultrapassada. O tema do "grande escritor" é o mais recorrente nos comentários de Barthes sobre Malraux. Em uma entrevista

*( $: 1148)$

*(I: 815.)

" "emboucher la trompette de I'humanité où [il] est imbattable" (I: 814.815)

" "La hauteur est une vertu d'écriture, un drapé d'âme, ici l'alexandrin, là le cas tillanisme des passions" (I: 815) 

as idéias prontas", Barthes afirma:

A literatura foi um objeto definido historicamente por um certo tipo de sociedade. Mudando a sociedade, inelutavelmente, seja em um sentido revolucionário, seja em um sentido capitalista, a literatura (no sentido institucional, ideológico e estético que recentemente dávamos a essa palavra) passa: ela poderá abolirse completamente ou modificar a tal ponto suas condições de produção, de consumo e de escritura, em suma, seu valor, que será preciso mudar o seu nome. Que resta das formas da antiga literatura? Algumas formas discursivas, editoras, um público frágil, infiel, minado pela cultura de massa, que não é literária: os grandes dominadores da literatura se afastam: depois de Aragon e Malraux, não haverá mais "grandes escritores".
La littérature a été un objet défini historiquement par un certain type de société. La société changeant, inéluctablement, soit dans un sens révolutionnaire, soit dans un sens capitaliste, la littérature (au sens institutionnel, idéologique et esthétique que nous donnions naguère à ce mot) passe: elle pourra ou s'abolir complètementou modifier à tel point ses conditions de production, de consommation et d'écriture, bref sa valeur, qu'il faudra bien en changer le nom. Que reste-t-il déjà des formes de l'ancienne littérature? Quelques modes de discours, des maisons d'édition, un public fragile, infidèle, miné par la culture de masse, qui n'est pas littéraire: les grands mainteneurs de littérature s'éloignent: Aragon et Malraux disparus, il n'y aura plus de "grands écrivains"*.

Barthes volta a essa mesma noção em uma conversa com Maurice Nadeau ("Para onde vai a literatura?”):

Constata-se um abandono, por assim dizer nacional e social, da grande literatura e de seu mito. [...] Do mito do escritor também, pois atualmente nenhum escritor ocupa o lugar que ocupavam pessoas como Valéry, como Gide, como Claudel, ou mesmo como Malraux, naquela época. $^{3}$
On constate un abandon, en quelque sorte national et social, de la grande littérature et de son mythe. $[\ldots]$ Du mythe de l'écrivain également, car actuellement, aucun écrivain ne tient la place que tenaient des gens comme Valéry, comme Gide, comme Claudel, même comme Malraux à cette époque*.

${ }^{3}$ Barthes volta ainda a esse assunto em conversa com Jacques Chancel a 17 de fevereiro de 1975 (III, 345), no "Prefácio-debate a Literatura Ocidental". Paris: R. Laffont, 1976 (III :429). 
Segundo Barthes, Malraux pertence portanto à era da literatura que está, na melhor das hipóteses, apodrecendo, ou na pior, já morta. O "grande escritor", a figura do grande mestre não tem mais razão de ser. Deve assim ser o objeto de uma desfetichização, que Barthes define como um empreendimento próprio de seu gesto crítico, como o que aprendeu com seus mestres, Marx e Sartre:

$\mathrm{O}$ que um e outro me ensinaram (acredito, em suma, que é o que os une, talvez até a única coisa que os una), é um desenvolvimento agudo do poder crítico que chamarei, de um modo mais pretensioso, porém mais justo também, de poder de "desfetichização", uma energia constantemente em alerta para desfetichizar os valores, os ídolos, os ritos da instituição social.
Ce qu'ils m’ont apporté essentiellement l'un et l'autre (je crois du reste que c'est ce qui les réunit, peut-être même la seule chose qui les réunit), c'est un développement aigu du pouvoir critique que j'appellerai, d'une façon plus prétentieuse, mais plus juste aussi, le pouvoir de "défétichisation", l'énergie sans cesse en alerte pour défétichiser les valeurs, les idoles, les rites de l'institution sociale*.
* (II: 989)

Mas Sartre? Não é precisamente durante os anos 1970, com Aragon e Malraux, o verdadeiro exemplo do "grande escritor" engajado? Para Barthes, Sartre escapa a seu estatuto pelo fato de representar menos a figura do "grande escritor" do que sua encarnação irônica. É o que confia a Jacques Chancel em conversa que data de 1975 :

Há um homem que faz a articulação, que se situa justamente no ponto de desagregação histórica da literatura: é Sartre. Porque, no fundo, ele teve e mantém ainda essa espécie de liderança da cultura e da literatura; mas como sua obra se define precisamente como uma destruição da aparência literária, da prosa literária, foi por essa mesma razão que contribuiu poderosamente para a destruição do mito literário.
Il y a un homme qui fait la charnière, qui se situe justement au point de désagrégation historique de la littérature, c'est Sartre. Parce qu'au fond il a tenu et tient encore cette sorte de leadership de la culture et de la littérature; mais comme précisément son œuvre même se définit comme une destruction du semblant littéraire, de la prose littéraire, par là même, il a contribué puissamment à la destruction du mythe littéraire*. 
- “acte radical par lequel un certain nombre d'écrivains ont tenté de nier la litté rature comme système mythique" (I: 702)
- "Le style est une subs. tance sans cesse menacée de formalisation: d'abord il peut très bien se dé. grader en écriture: il y a une écriture-Malraux, et chez Malraux lui-même" (I:701)
" “(..) fait éclater les contraintes de la lisibilité classique, c'est-à-dire les textes que la plupart d'entre nous déclarent illisibles, mais qui, à partir du moment où l'on essaie de réinventer une façon de lire devient un texte exem plaire, parce que c'est précisément un texte où le signifié, comme nous le disions tout à l'heure, est expulsé vraiment à l'infini, et où demeure simplement un réseau extrêmement proliférant de signifiants" (II: 994)
Sartre ocupa, portanto, uma posição dupla: é, ao mesmo tempo, última encarnação e destruidor do "grande escritor" desfetichizador de si próprio.

Mas tornemos a Malraux, atravessemos com Barthes a última etapa da ocultação desfetichizante: se Malraux é um conservador, é porque pertence a um tempo ultrapassado da escritura e conserva, por isso mesmo, formas ultrapassadas de literatura. Desliza-se do personagem do "grande escritor" a uma prática da escritura que lhe é associada e que se poderia definir como uma confiança na linguagem, ou, em termos sartrianos, como o exercício de uma escritura literária da "boa consciência”. Em "O mito hoje”, apêndice a suas Mitologias, de 1957, Barthes evoca o seu Grau zero da escritura: atualização da "subversão da escritura", do desvelamento próprio da modernidade literária (que Barthes faz remontar a Flaubert), da escritura "como significante", como "ato radical pelo qual um certo número de escritores tentaram negar a literatura como sistema mítico"*.

Ora uma nota visa precisamente colocar Malraux fora dessa revolução da literatura moderna: há um "estilo Malraux", e portanto uma consciência do trabalho da escritura como jogo com o significante, mas a nota precisa: "O estilo é uma substância sempre ameaçada de formalização: primeiramente, pode muito bem degradar-se em escritura: há uma escritura-Malraux e no próprio Malraux"*.

Encontramos a acusação de formalismo, mas deslocada do discurso para a escritura, do homem para a obra. Então, que mito colocar no lugar do "grande escritor"? Onde está a literatura, se abandonou seu campo tradicional? Para onde vai a literatura após a ruptura epistemológica da modernidade? Quem é, para Barthes, verdadeiramente escritor? É aquele cujo texto "faz explodir as regras da legibilidade clássica, ou seja, os textos que a maior parte de nós declara ilegíveis, mas que, a partir do momento em que se tenta reinventar um modo de ler, tornase um texto exemplar, porque se trata precisamente de um texto cujo significado, como há pouco dizíamos, é expulso para sempre, e em que permanece simplesmente uma rede extremamente proliferante de significantes"*. Barthes reconhece nessa definição um texto e um escritor: é Sollers. Em Sollers escritor, em 1979, a propósito de $\mathrm{He}$ de seu modo de leitura, Barthes escreve: 
O texto se propõe a leitores que não vivem no mesmo tempo de leitura (mesmo que sejam biograficamente contemporâneos). Alguns querem ler $H$ como um romance (e ficam decepcionados); outros estão na vanguarda de 1930; outros se colocam enfim postulativamente no futuro ( $\mathrm{CO}-$ mo se, amanhã, não devesse ser mais este texto), sabendo que esse futuro não é só progressivo e que ele comporta dialeticamente retornos, contratempos: um leitor de Dante ou de Rabelais está provavelmente mais próximo de $H$ do que um leitor de Malraux.
Le texte s'offre à des lecteurs qui ne vivent pas dans le même temps de lecture (même s'ils sont biographiquement contemporains). Certains veulent lire $H$ comme un roman (et ils sont déçus); d'autres sont dans l'avantgarde de 1930; d'autres se mettent enfin postulativement dans l'avenir (même si, demain, ce ne sera pas ce texte-là), en sachant que cet avenir n'est pas seulement progressif et qu'il comporte dialectiquement des retours, des contretemps: un lecteur de Dante ou de Rabelais est sans doute plus proche de Hqu'un lecteur de Malraux.*
(III : 959)

(Jouve, Vincent. Poétique des valeurs. Paris, Seuil, 2001) 
Cabe a ela também, mas o trabalho ainda está em curso ${ }^{4}$, retirar a obra malruciana do purgatório em que o terrorismo textual da nova crítica a lançou, e revelar com força a modernidade poética dos textos e o conjunto de tudo aquilo que a obra pode dizernos sobre os avanços da literatura moderna e contemporânea.

Tradução

Edson Rosa da Silva

[UFRJ]

${ }^{4}$ Remetemos o leitor aos trabalhos de Henri Godard e de Jean-Claude Larrat sobre a concepção da literatura malruciana, e de Jacques Lecarme sobre a contribuição para uma teoria e prática da autobiografia. 
Julien Dieudonné

Professor em Paris III, Sorbonne Nouvelle. É autor de uma tese sobre Jean Paulhan, publicada pela editora Champion sob o título Recits de Jean Paulhan, e possui diversos artigos sobre escritores do século XX, dentre os quais André Malraux. Participa dos comitês de redação da revista Lettres Modernes, série André Malraux, e da revista Présence d'André Malraux.

\section{Resumo}

O artigo aborda, através da ocultação que Roland Barthes faz da obra de André Malraux, o desafeto de que goza o autor de Condição humana na França atual. Considerado como um escritor que abandonou sua posição de esquerda ao assumir um cargo político ao lado de De Gaulle, Malraux deixa de ser apreciado como um escritor revolucionário. Barthes quase não cita Malraux ou o cita sempre com o intuito da desmistificação, tanto do escritor quanto do ministro. $\mathrm{O}$ artigo tenta, por meio de uma ironia fina, opor-se ao crítico Roland Barthes e resgatar o lugar do romancista dos anos 1930 no panorama da literatura francesa.

\section{Abstract}

This article treats the current dislike in France for Malraux, author of the novel Man'sfate, by discussing the almost complete absence of reference to his works by Roland Barthes. Malraux is considered to have abandoned his leftist revolutionary stance after accepting political office next to Minister De Gaulle. Barthes almost never mentions Malraux or does it in order to discredit the writer and the Minister he works for. This article tries, through fine irony, to offer an alternative to Barthes' view and attempts to recover Malraux's place in the panorama of French literature from the 1930's.

\section{Résumé}

L'article aborde, à travers l'occultation que Roland Barthes fait de l'oeuvre d'André Malraux, la désaffection dont jouit l'auteur de La condition humaine dans la France actuelle. Considéré comme un écrivain qui a abandonné sa position à gauche quand il assume une fonction politique à côté de De Gaulle, Malraux ne se fait plus apprécier comme un écrivain révolutionnaire. Barthes ne le cite pas ou le cite toujours avec l'intention de démystifier son oeuvre, tant celle de l'écrivain que celle du Ministre. L'article essaie, moyennant une fine ironie, de s'opposer au critique Roland Barthes et de faire récupérer sa place à l'écrivain des années 1930 dans le panorama de la littérature française.

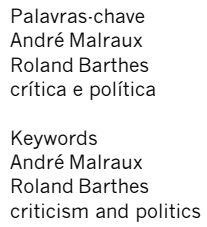

Recebido em 28/01/2003 Aprovado em 12/07/2003 